\title{
EDUCAÇÃO E TRABALHO: A ORIENTAÇÃO VOCACIONAL/PROFISSIONAL COM JOVENS DE ESCOLA PÚBLICA
}

\author{
Fernando César Paulino-Pereira* \\ Ramon Arthur Jacinto da Silva**
}

Resumo: Este trabalho procura investigar os efeitos do trabalho em grupo e relatar o caminho percorrido por um projeto de extensão em Orientação Vocacional/Profissional (OVP) em uma escola específica da rede pública da cidade de Catalão, em conjunto com o curso de Psicologia da Universidade Federal de Goiás - Campus Catalão. A perspectiva sócio-histórica da Psicologia Social foi adotada como base teórica, pois, para permitir uma melhor compreensão do fenômeno da escolha profissional, basicamente depõe nas relações sociais e da linguagem, construindo os alicerces na edificação do sujeito humano. Com o objetivo de inserir a OVP nas escolas, utilizando-se de técnicas de intervenção grupal, por meio da pesquisa-ação e o diário de campo, perceberam-se pontos positivos significativos que podem conceder à OVP status de contribuinte para as escolhas profissionais dos jovens de baixa renda.

Palavras-chave: Orientação Vocacional/Profissional. Educação. Trabalho. 
Abstract: This study investigates the effects of work group and report the path of an extension project on Vocational Guidance/Professional (VGP) on a specific public school in Catalão city, with the course of Psychology in Federal University of Goiás, Campus Catalão. The Socio-historical perspective of Social Psychology was adopted as the theoretical basis for, to enable a better understanding of the career choice phenomenon, basically deposes in social relations and language, building the foundation in building the human subject. Aiming to put the VGP in schools, using techniques of group intervention, throught action-research and the field diary, it was noted that significant positives may grant the status of VGP contributor to the career choices of low-income youth.

Keywords: Vocational Guidance / Professional. Education. Work. 


\section{Introdução}

Este trabalho é o resultado conclusivo de um projeto de extensão em Orientação Vocacional/Profissional (OVP), ofertado, desde 2010 pelo curso de Psicologia do Campus Catalão da Universidade Federal de Goiás (CAC/UFG), semestralmente à comunidade e a alunos da rede pública de ensino médio da cidade de Catalão (Goiás), com o intuito de orientar àqueles que procuram auxílio durante o processo da escolha profissional. Tal projeto foi auferido em 2011 com duas bolsas pela Pró-Reitoria de Extensão e Cultura (Proec), sendo uma remunerada e outra voluntária, a partir do Programa de Bolsas de Extensão e Cultura (Probec) e do Programa de Voluntários de Extensão e Cultura (Provec), respectivamente.

A OVP foi realizada tendo como referencial teórico/metodológico a Psicologia Social, numa abordagem sócio-histórica. O projeto passou por duas etapas: primeiramente, a discussão teórica por meio de seminários dialogados e debatidos acerca da teoria, das propostas de trabalho e intervenção e das técnicas de oficinas em grupo da OVP; posteriormente, efetivação de atividades de intervenções anteriormente medradas e edificadas em supervisão para em seguida serem trabalhadas com alunos da Rede Pública de Ensino Médio, enfatizando sempre a atualidade da escolha profissional no Brasil.

A busca pelo processo emancipatório dos jovens de escola pública teve como foco sete itens: socialização em grupo; autoconhecimento; família; amigos/escola; situação socioeconômica atual do País; profissões; e conclusão. Estes itens foram subdivididos em cinco encontros, todos trabalhados em grupo, discutidos até a escassez de dúvidas referentes aos temas. 
Pensar a OVP em escolas públicas é refletir uma possibilidade de auxílio a jovens negligenciados pelo social, marginalizados com ideias preconcebidas de que os menos favorecidos financeiramente não têm direito de escolher sua profissão, reafirmando uma conjectura de ser desprovido, violentado pela situação econômica.

Numa abordagem qualitativa, por meio da pesquisa-ação, foi possível refletir sobre a importância da implementação da OVP nas escolas públicas do município, tentando não apenas atender uma demanda, mas também propiciando a difusão de tal conhecimento de forma acessível.

\section{Revisão de literatura}

\section{A Orientação Vocacional Profissional (OVP)}

Segundo Carvalho (1995), o surgimento da orientação vocacional foi minuciosamente atrelado com o desenvolvimento da indústria em conjunto com profissionais da educação, sempre com o intuito de adequar o indivíduo ao trabalho. $\mathrm{O}$ trabalho, antes tido como um direito conquistado pela classe trabalhadora, transforma-se em mercadoria, um contexto neoliberal onde, inclusive, o Estado se torna escravo do mercado. O primeiro centro de OVP surgiu na Baviera, no ano de 1902, para que pudessem identificar indivíduos destituídos de vocação para um trabalho específico, prevenindo-se de possíveis acidentes.

A mesma autora relata que, no Brasil, o seu surgimento foi possível por intermédio de um engenheiro suíço, em 1924, depois 
do surgimento de muitas outras instituições ao redor do mundo adotando a OVP. Isso mostra que o uso da Orientação Vocacional Profissional vem sendo aplicada desde a década de 1920 em âmbitos industriais, escolares e até mesmo na clínica, antes mesmo da regulamentação da Psicologia na década de 1960.

Em 1958 já existia uma disciplina "Seleção e Orientação Profissional" como estágio obrigatório e supervisionado no $5^{\circ}$ ano de graduação na Universidade de São Paulo (USP), instituição fundadora do curso de Graduação em Psicologia, tendo a disciplina "Seleção e Orientação Profissional”. Em 1968 a disciplina foi desmembrada em duas distintas, uma de "Seleção" e outra de "Orientação Profissional”. Após isso, alguns estudos situam "[...] a orientação vocacional na Psicologia do Trabalho, outros na Psicologia Educacional, outros na área da Orientação ou do Aconselhamento e, mais recentemente, apresentando a Orientação Profissional como uma área em si." (CARVALHO, 1995, p. 26).

Carvalho (1995) nos ajuda a refletir que as dificuldades dos jovens em relação a uma escolha profissional sempre estão atreladas a não definição de um autoconceito; à insegurança; à falta de informações sobre os cursos, o mercado de trabalho e as profissões, bem como a medos que fazem parte do momento psicossocial da adolescência. Por assim ser, a informação vocacional e profissional torna-se indispensável por se tratar de um instrumento que favorece a descristalização daquilo que cada jovem absorveu no transcorrer de sua história.

A proposta inicial da OVP era trabalhar individualmente com aqueles que procuravam pelo serviço. Quando em contato com essas pessoas, suas demandas eram impregnadas com problemáticas de valores grupais e influências, assim como a dependência destas. Fez-se então necessária, por falta de material na área, a pesquisa e 
a elaboração de maneiras de se trabalhar com pequenos grupos, já que, além da grande procura por este serviço, era necessário abranger temas coletivos (CARVALHO, 1995).

Com o desenvolvimento da OVP no Brasil, em 1993 foi realizado o I Simpósio Brasileiro de Orientação Vocacional/Ocupacional, em Porto Alegre (RS), o qual, atualmente, encontra-se na sua XI edição. Durante o primeiro evento, foi fundada a Associação Brasileira de Orientadores Profissionais (ABOP), constituída a partir de valores éticos, rigor científico e compromisso com a população na prestação de serviços, na pesquisa e na formação de orientadores profissionais, assim como a missão de desenvolver, integrar e valorizar a orientação profissional no Brasil.

A partir do histórico que a OVP vem construindo, Santos (1963 apud CARVALHO, 1995, p. 41) nos esclarece que:

A Orientação é o processo de fazer o indivíduo descobrir e usar seus dotes naturais e tomar ciência das fontes de treinamento disponíveis, a fim de que possa viver de modo a tirar o máximo proveito para si próprio e para a sociedade.

Para isso, é necessário que o psicólogo aja de forma compreensível e atuante com o orientando, descobrindo e trabalhando tudo que englobe a sua identidade, ou seja, tudo no âmbito "biológico, psicológico, social, cultural e histórico", bem como as circunstâncias do momento da escolha, sejam elas subjetivas ou objetivas, sejam elas externas ao indivíduo.

O indivíduo sujeito da história é constituído de suas relações sociais e é, ao mesmo tempo, passivo e ativo (determinado e determinante). Ser mais ou menos atuante como sujeito da história depende do grau de autonomia e iniciativa que ele alcança. (LANE, 2004, p. 40). 
Todo indivíduo aprende a ser homem por um processo de humanização a partir da cristalização da linguagem materna, e, com isso, “[...] enquanto produto histórico, traz representações, significados e valores existentes em um grupo social, e como tal, é veículo da ideologia do grupo." (LANE, 2004, p. 41). Tal ideologia perpassa pelo indivíduo, tomando aquilo para si.

Assim como a linguagem insere o sujeito na história de sua sociedade, ela também desenvolve a consciência de si e social de indivíduo. Ser humano nada mais é que uma manifestação de uma totalidade histórico-social, de um pensamento e de ações de trabalho que o indivíduo realiza juntamente com outros indivíduos (LANE, 2004). Juntamente com a linguagem, o trabalho é outra manifestação do ser "homem"; constrói e molda o indivíduo e, consequentemente, este, a sociedade. Sendo assim, a linguagem e o trabalho, como produtos de uma coletividade, produzem e reproduzem significados/signos em que o indivíduo mobiliza imagens construídas a partir de sua vivência social, cristalizando esses significados/signos de um determinado papel/profissão.

A aquisição da linguagem, a grande produção de conhecimentos que a humanidade acumula, assim como as produções de habilidades e capacidades de intervenção do homem na realidade, geram a atividade produtiva e, consecutivamente, os conteúdos da educação. Há, portanto, uma relação íntima entre a aprendizagem - seja ela da linguagem, seja ela das habilidades - e o trabalho.

Em um processo de OVP, é de extrema importância a análise ideológica para o conhecimento psicossocial, já que é ela determina a constituição do sujeito a partir de sua rede de relações sociais e comportamentos. Mas tal análise só é possível no plano individual, já que, mediados pela linguagem, é um processo que envolve 
pensamento e ação. Como Lane (2004, p. 43) nos diria sobre o fazer ou não fazer:

[...] ação e não-ação só podem coexistir no pensamento; enquanto atividade ou o indivíduo age ou não-age, tornando o pensar uma atividade fundamental, prevendo conseqüências e levando a uma decisão que se transforma em ação ou não-ação.

Esse pensar pode ser apenas reproduzido, tomado como verdade, pois, se não ocorrer a reflexão, o pensar a ação já se caracteriza como verdadeiro, reduzindo a uma ideologia alienadora. A ação e não ação, fazer e não fazer, agir e não agir, feito e não feito de um indivíduo é um produto subjetivo e reproduz sua ideologia juntamente com suas especificidades, trazendo confrontos do dia a dia para sua vida. Se tais confrontos forem pensados e questionados, gerará contradições, no qual acontecerá então um avanço no processo de conscientização.

O estabelecimento de papéis (estudante, filho, médico, psicólogo etc.) a serem desempenhados levam à cristalização destes personagens, sendo que tais papéis são vistos como tendo uma realidade própria e exterior aos indivíduos. Estes se revestem da realidade ao se submeterem-se aos papéis, incorporados sob a forma de crenças e valores transmitidos pela socialização primária, a família, e pela socialização secundária, tudo decorrente da própria complexidade existente nas relações de produção. Para tal, cabe à OVP “[...] apreender como se dá esta internalização da realidade [...] e como ela faz a mediação na determinação dos comportamentos dos indivíduos [...]" (LANE, 2004, p. 84) diante de suas escolhas a partir da realidade subjetiva e objetiva. 


\section{Justificativa}

É de grande relevância e importância refletir sobre a OVP nas escolas e problematizá-la no âmbito do estudo da psicologia. Primeiramente, porque versar a OVP junto ao público jovem não é simplesmente atender a uma demanda que encontra-se carente, mas sim abordá-la de forma consciente e que promova a autorreflexão. É levar a psicologia às escolas públicas de forma acessível, evidenciando que dentro da escola também é lugar de se discutir sobre trabalho, papel este que é do psicólogo.

Além da falta de informação dos jovens das escolas públicas de Catalão (GO) quanto às profissões e mercado de trabalho, esta pesquisa-ação justifica-se por contribuir cientificamente para a área da OVP; colaborar e auxiliar os estudantes de Psicologia em seu processo de formação profissional, como também ter uma produção científica que contribua para que o psicólogo atue com essa população em específico, jovens carentes de escola pública. Contribuição na implementação de projetos de intervenção, em contexto escolar, que promovam práticas emancipadoras.

Pensar em integração entre teorias e práticas psicológicas é papel do psicólogo social. Neste trabalho, teve-se como fim propor ações que visassem a transformação da realidade psicológica do grupo, além de também contribuir para avultar e eclodir os campos de atuação da Psicologia.

De acordo com Melo Neto (2003) e Reboredo (1995), o psicólogo deve elaborar sua pesquisa-ação como uma práxis que instigue o conhecimento para sua área, assim como retornar de forma compromissada este conhecimento adquirido ao grupo estudado e trabalhado. 
$\mathrm{Na}$ atividade do psicólogo, teoria e prática devem ter a mesma relevância científica, pois 'não se pode realizar prática criativa sem retorno constante à teoria, bem como não se pode fecundar a teoria, sem confronto com a prática'. (REBOREDO, 1995 p.16).

\section{Objetivos}

Geral: estudar as contribuições da OVP com adolescentes de escolas públicas na cidade de Catalão (GO), a partir de atividades teórico/práticas da Psicologia Social.

Específico: compreender a importância da atuação do psicólogo dentro das escolas públicas por meio da intervenção grupal; auxiliar os jovens de escola pública a compreender as diferentes formas de atuar na escolha profissional; estudar as contribuições da OVP na escolha profissional; inserir a OVP nas escolas públicas da cidade de Catalão (GO).

\section{Método}

A estratégia metodológica utilizada para a elaboração deste trabalho foi a participação ativa de um grupo de alunos da escola pública Anice Cecílio Pedreiro, na cidade de Catalão (GO) por meio da pesquisa-ação, com divulgação, orientação, acolhimento de jovens e oficinas terapêutico-educativas. Após a vivência de cada momento trabalhado nos grupos de OVP, era elaborado um diário de campo que, segundo Pelissari (1998), é uma forma de registrar o que se olha, como se olha e o que se faz com o que é vis- 
to. Estas anotações foram utilizadas como base para as propostas realizadas no grupo e fundamentação do presente trabalho.

Levando-se em conta os objetivos formulados, adotou-se uma abordagem qualitativa de pesquisa, a pesquisa-ação, entendida como “[...] uma forma de investigação-ação que utiliza técnicas de pesquisa consagradas para informar a ação que se decide tomar para melhorar a prática." (TRIPP, 2005, p. 447).

Para Franco (2005), revelou-se que no Brasil a pesquisa-ação tem recebido pelo menos três conceituações diferentes para análise de estudos realizados recentemente, podendo ser crítica, colaborativa e estratégica. A metodologia de pesquisa utilizada neste estudo aproxima-se bastante da pesquisa-ação crítica, visto que esta leva em consideração:

[...] a voz do sujeito, sua perspectiva, seu sentido, mas não apenas para registro e posterior interpretação do pesquisador: a voz do sujeito fará parte da tessitura da metodologia da investigação. [...] Daí a ênfase no caráter formativo dessa modalidade de pesquisa, pois o sujeito deve tomar consciência das transformações que vão ocorrendo em si e no processo. É também por isso que tal metodologia assume o caráter emancipatório, pois mediante a participação consciente, os sujeitos da pesquisa passam a ter oportunidade de se libertar de mitos e preconceitos que organizam suas defesas à mudança e reorganizam a sua autoconcepção de sujeitos históricos. (FRANCO, 2005 p. 486).

Tal método de investigação foi escolhido porque, segundo Tripp (2003, p. 448), “[...] a pesquisa-ação é participativa na medida em que inclui todos os que, de um modo ou de outro, estão envolvidos nela e é colaborativa em seu modo de trabalhar [...]”, como também “[...] o participante é conduzido à produção do próprio conhecimento e se torna sujeito desta produção." (MELO NETO, 
2003, p. 2). Ou seja, os próprios participantes também ocupam os lugares de transmissores e receptores de informação.

O grupo foi formado por dez integrantes no início do trabalho, cinco garotas e cinco garotos. A quantidade variou durante o processo e finalizou com oito integrantes, sendo sete garotas e um garoto, em uma faixa etária entre 15 a 18 anos, formado por alunos do Ensino Médio do Colégio Estadual Anice Cecílio Pedreiro

O protocolo de aplicação, utilizado no projeto, conta com 11 encontros ao todo, porém com dez temas diferenciados, sendo eles: 1) conhecer os componentes do grupo, seus interesses e expectativas em relação ao trabalho; 2) esclarecer sobre o processo de Orientação Profissional. Instalar normas de convivência grupal e discutir a importância do respeito e sigilo em relação ao conteúdo específico de cada colega do grupo; 3 ) iniciar reflexão sobre a história de vida do indivíduo no contexto familiar e a escolha profissional; 4) iniciar reflexão sobre a individualidade. Análise de autoconhecimento; 5) refletir sobre os grupos de amigos e a escolha profissional; 6) iniciar reflexão sobre a experiência da vida escolar; 7) analisar os contextos socioeconômicos do País, atual e futuro e sua relação com o mercado de trabalho; 8) investigar e/ ou analisar a diversidade de profissões do mercado de trabalho; 9) elaboração de síntese final do processo já com escolhas profissionais definidas; 10) avaliação final do processo.

Nesta pesquisa, foi trabalhado outro protocolo com apenas cinco encontros, devido à proximidade do fim do semestre letivo. Essa sintetização feita em cinco encontros nada mais é do que uma condensação crítica e minuciosa de todos os temas abordados nas discussões e dinâmicas dos 11 encontros, para que não haja prejuízo quanto à qualidade do trabalho. 


\section{Resultados e discussão}

A turma trabalhada era relativamente grande, porém com desistências sem justificativa de alguns jovens durante o processo. O grupo de alunos que constituía a turma já havia percorrido um longo período juntos, mas mesmo assim não foram descartadas as apresentações. No primeiro encontro, o principal objetivo é promover a interação entre os integrantes, o conhecimento das regras de convivência e adquirir mais informações sobre o trabalho em OVP.

Para possibilitar uma melhor compreensão sobre o funcionamento do trabalho em OVP e os temas, pelos participantes e dos coordenadores sobre os participantes, os debates e as discussões subterfugiram atividades lúdicas, tais como jogos de perguntas gerais e técnicas de intervenção grupal. Vídeos, jornais e revistas também foram ferramentas utilizadas para se trabalhar a importância de estar informado sobre as profissões e o mercado de trabalho.

A apresentação inicial foi promovida por dinâmicas de grupo, que permitiam aos jovens a ambientação de forma descontraída, participativa e congruente. Usualmente, quando se trata de turmas grandes, é utilizada a "dinâmica do fósforo" por ser mais prática, consistindo-se na pessoa apresentar-se da forma mais completa possível enquanto o fósforo estiver queimando. Outra dinâmica usada com qualquer quantidade de integrantes, muitos ou poucos, chama-se "anúncios classificados". Trata-se de escrever em um papel um anúncio de classificados, como se vê em jornais, oferecendo-se para algum serviço, curso ou outra coisa.

Durante o processo em que todos se conheciam, alguns faziam perguntas direcionadas tanto aos outros participantes, quanto também aos orientadores com humor na fala, tais como: "O que vocês 
(orientadores) vão fazer com a gente é um estágio ou o quê? Lavagem cerebral? Onde estão os testes psicológicos?” (cf. Diário de campo, 17 de maio de 2011). Tais perguntas, além de mostrar a falta de informação quanto ao trabalho de OVP, mostram também interesses por parte dos alunos em relação ao trabalho que será realizado e uma ilusão de uma psicologia tradicionalista, predominantemente clínica, hegemônica no campo da Psicologia Geral.

Seguindo o protocolo de aplicação, os participantes foram esclarecidos quanto ao sigilo, à diligência e à assiduidade, firmando assim o contrato. Logo após o contrato ser consolidado, todas as informações foram transmitidas de como escoarão os encontros ulteriores e os respectivos temas.

Tratando-se de apresentações e das regras referentes ao convívio em grupo, tais como sigilo e respeito ao próximo, todos expuseram que a amizade entre os membros da turma era de longa data e em um determinado momento R. A. disse: "Aqui na sala já existe regras de boa vizinhança." (cf. Diário de campo, 17 de maio de 2011).

Ainda no primeiro encontro, após promover o entrosamento, colher informações básicas de cada integrante, estabelecer o contrato grupal e expor, em um debate, sobre o funcionamento da OVP, foi distribuído um questionário com perguntas abrangentes referentes aos temas abordados, além dos dados pessoais para enriquecer o material recolhido.

No segundo encontro, o tema abordado priorizava assuntos como família e autoconhecimento, do qual a turma participou com muito interesse, pois nunca ninguém conversou abertamente com eles sobre tais conteúdos. Porém, quando era orientada ou sugerida alguma fala, todos se calavam, de modo que apenas após algum incentivo, direcionando a pergunta a alguém em especí- 
fico, as falas ocorreriam livremente. A partir de então, os alunos articulavam suas ideias; escutavam e opinavam na fala de seus colegas, esclarecendo sobre novas possibilidades em determinados temas; bem como mostrando os erros e acertos de seus amigos, e até os seus próprios.

Assim como afirmam Bock e Aguiar (1995), o autoconhecimento não deve ser trabalhado apenas na identificação de aptidões, interesses e características inatas ou adquiridas, mas sim o porquê atrás daquela escolha, daquele momento de sua história, assim como as expectativas familiares.

Em suas falas, os jovens demonstraram ter grande ligação com seus familiares, pois, no desenvolvimento da temática, quando eram questionados sobre pontos positivos e negativos que envolviam a família, os aspectos positivos se sobrepunham; em uma das atividades desenvolvidas, em que eram questionados sobre qual outra pessoa gostariam de ser, famosa ou não, muitos escolheram seus familiares, tal como T. C., quando disse que “[...] gostaria de ser minha mãe, pois ela sabe se colocar na hora certa e sempre acerta, é uma ótima conselheira." (cf. Diário de campo, 24 de maio de 2011).

Bock e Aguiar (1995) apontam que o jovem que passa por este momento tem expectativas familiares e sociais. Se o jovem não corresponde ao esperado, os problemas surgirão de forma violenta. Analisando o grupo, muitos dos integrantes disseram que os pais realmente têm expectativas, porém a vontade de ver seus filhos felizes é maior.

Todo indivíduo aprende a ser homem por um processo de humanização que se consolida a partir da linguagem e, com isso, “[...] enquanto produto histórico, traz representações, significados e valores existentes em um grupo social, e como tal, [a linguagem] é veículo da ideologia do grupo.” (LANE, 2004, p. 41). A linguagem, 
como produto de uma coletividade/grupo, reproduz significados/ signos, de modo que o indivíduo mobiliza e cristaliza uma imagem construída de si mesmo e dos outros a partir de sua vivência construída por meio de contatos pessoais.

Com o intuito de promover o autoconhecimento destes jovens, foi proposta uma atividade que consistia em olharem no espelho, refletirem sobre a pessoa para qual olhavam e falarem adjetivos positivos e negativos. Após todos falarem os adjetivos, o enfrentamento (aqui visto como ato de opor-se à opinião dada) era necessário, para saber se seus companheiros de classe os viam da mesma forma. A própria visão que alguém tem de si mesmo faz parte de seu cotidiano, e Lane (2004) afirma que se o cotidiano for apenas agido leva à alienação. Assim, para que o indivíduo conscientize, é necessário se pensar, confrontar-se com a realidade.

Esse confronto mostrou-se interessante, pois após um dos alunos, D. N., ter se apresentado como alguém ansioso, "tagarela", engraçado e organizado, muitos dos colegas estranharam, já que este sempre mostrou-se alguém totalmente diferente da imagem que o conheciam.

Aqui estou para estudar, seguindo ou não o conselho de meus pais, viso meu futuro em uma universidade, cursando música. Em casa e na igreja, sou mais eu, diferente daqui. (cf. Diário de campo, 24 de maio de 2011).

Pode se dizer que seus colegas mobilizaram uma conjetura, uma imagem fundada em aparências, cristalizando-a de tal modo que não a viram de outra forma.

A longa convivência da turma mostrou como este grupo pode se tornar coeso, respeitador, compreensivo e com grande capacidade de reflexão, mas também poderão aparecer pensamentos 
controversos e opressivos que podem ter sentido ofensivo, como se mostrou a respeito de $\mathrm{D}$. N.

Ao final, todos puderam ler em voz alta a tarefa proposta no último encontro, uma carta descrevendo um tema simples, porém de grande dificuldade para se pensar: “Quem sou eu?”. Na análise das redações, perceberam-se questões do passado, do presente e do futuro. Muitos descreveram seu histórico de vida, onde nasceram, estudaram, quantos irmãos, onde já moraram. Descrições do atual momento familiar, afetivo e financeiro, como também características pessoais, descritas por meio de adjetivos. Em relação ao futuro, a maioria se colocou dentro de cursos universitários os quais pretendem fazer, almejando estabilidade e sucesso na carreira.

De acordo com Lane (2004, p. 84), a vivência subjetiva é marcada "[...] pela ideologia, onde cada um se representa como indivíduo livre, capaz de todas as realizações [...]”, do ir e vir, como pode-se ver na redação destes jovens, reproduzindo uma ideologia capitalista de conquistas fáceis. $\mathrm{O}$ trabalho em OVP provém também mostrar aos jovens que tais desejos também perpassará a realidade objetiva, "[...] onde as ações e interações estão sempre amalgamadas por papéis sociais que restringem essas interações ao nível do permitido e do desejado [...]" (LANE, 2004, p. 84), ou seja, a verdadeira realidade do sistema capitalista.

Frente a tal ideologia capitalista, Bock (2010) mantém a perspectiva de que a escolha das classes subalternas não é apenas ilusória. A discussão mantida no grupo de OVP foi de que há a possibilidade de ser ativo em sua própria história, intervir de certo modo sobre as condições sociais vigentes, sejam elas por ações pessoais, sejam elas por ações coletivas.

No terceiro encontro, a prioridade era temas nos quais todos dominavam muito bem: a amizade, a escola e o que ambas influen- 
ciavam na escolha profissional. No início, todos leram a tarefa de casa, uma produção textual com o tema "Carta de despedida do amigo". A maioria dos jovens escolheu amigos reais, outros inventaram. As cartas obtiveram um cunho plenamente emocional, com grandes lamentações por não se verem mais. Os motivos são diversos, como morar em outra cidade ou país, empregos distantes ou separação dos pais, mas a maioria engajou em colocar que o principal motivo foi estudar.

Bock e Aguiar (1995, p. 19) dizem que

[...] outra questão relevante a ser refletida [...] é a influência dos próprios colegas, ou do grupo de iguais, no processo de escolha. O grupo de amigos, sem dúvida, se constitui em um fator de pressão, e às vezes mais autoritário do que a família, impondo valores e comportamentos.

Ao todo, são jovens que se agrupam entre amigos e sabem que a amizade tem de ser verdadeira, discutem sobre tudo, mas afirmam que quando se trata de escolhas, principalmente a profissional, apesar de os amigos e familiares sempre aconselharem, a decisão final é sempre do próprio indivíduo. Isto pode ser percebido na fala de G. C., ao dizer que "a amizade influencia muito nas escolhas, mas é preciso escolher algo pra você." (cf. Diário de campo, 6 de junho de 2011).

Vale esclarecer que alguns se demonstraram inseguros para falar em público desde o primeiro encontro; outros não queriam sequer participar das atividades ou mesmo dormiram durante $o$ processo. No transcorrer das atividades propostas, os próprios companheiros instigaram seus colegas a responderem ou, quando os conheciam muito bem e tinham intimidade, responderam por 
seus amigos, fato acontecido com A. R., que sempre se comportou como medo da perda e com medo do ataque (defesas diante de situações novas):

[...] ela falava muito para completar as frases dos colegas, mas ficava muito quieta ao falar de si mesma. Seus amigos descobriram quando ela tentava esconder a verdade. Tem uma oportunidade de jogar futebol em São Paulo, mas não sabe se quer ir ou não por causa da família e dos amigos. (cf. Diário de campo, 31 de maio de 2011).

A escola, instituição que participa diretamente da socialização secundária na vida de sujeitos e transmissora de ideologias, tem uma relação de grande importância na obtenção de novos significados e sentidos. Lane (2004) afirma que significados são aquisições por meio da linguagem, assim quando Bock (2010, p. 39) diz que "[...] o homem atua transformando o mundo a partir de sua atividade [trabalho], mas não internaliza os objetos, nem os seus gestos, mas a sua significação."

Quando trabalhado este módulo, uma das tarefas era mencionar uma disciplina e um professor que mais lhes agradavam. Mesmo essa estratégia parecendo ser simples, demonstra aquilo que acabamos de mencionar, a aquisição de sentidos. "Cada indivíduo constrói sentidos a partir de suas vivências, e esses sentidos, que são sempre singulares, envolvem emoções que geram motivos." (BOCK, 2010, p. 47).

A. R. menciona que odeia português, mesmo a professora sendo ótima, ou então M. B. adora espanhol, mas considera a professora despreparada, como também, diferente da maioria dos colegas, não gosta do professor de matemática, prefere a de português (cf. Diário de campo, 31 de maio de 2011). Estes motivos declarados 
pelos alunos são particulares, construídos por vivências subjetivas e intransferíveis, construídos e adquiridos historicamente e socialmente por sentidos.

No quarto encontro, o objetivo central era analisar o potencial crítico sobre a situação socioeconômica atual do País e a relação futura dos jovens com o mercado de trabalho, bem como a relação desses fatores com a escolha profissional; os jovens afirmaram acreditar que um curso superior deve ser escolhido por afinidades e, a partir disso, deve-se optar por aquele que trará estabilidade profissional e contínua de forma progressiva, bem como por aquele que propiciará qualidade de vida e gratificação financeira. Isto foi apresentado na fala de G. U., ao dizer que "as chances de ser melhor caso goste [do curso] são maiores do que alguém que faz por dinheiro." (cf. Diário de campo, 6 de junho de 2011). Vale ressaltar que, no grupo em questão, muitos jovens não acompanham com frequência noticiários, jornais, documentários ou qualquer outro veículo de comunicação que apresenta temas e informações referentes à economia.

Nesse quesito, ainda falta um pouco de "malícia” a estes jovens, que moram com os pais e a maioria ainda não conhece o mercado de trabalho, sujeitos alienados. Aberta a roda de discussão, a conversa teve um teor mais crítico, como exemplifica a fala de Bock (2010, p. 101):

[...] o mercado de trabalho é difícil, pois é lugar de concorrência, de conflito, de busca constante de capacitação. É lugar de incerteza quanto à possibilidade de se sair bem, de dúvida se o que vai conseguir com seu trabalho de fato recompensará o esforço pessoal despendido. O mercado é enigmático. O sujeito só conhece a necessidade de competência profissional como condição para enfrentá-lo 
Os jovens já estão inscritos no mercado de trabalho desde muito cedo, de tal maneira que estes não o percebem. São expectativas de familiares, professores, amigos e conhecidos, de profissões aceitas por proporcionarem rápida ascensão socioeconômica, mesmo que a população esteja mudando, vendo que o modelo universitário está se esgotando, tendo que procurar outras opções, como trabalhar fora do País ou como autônomos (SILVA, 1995).

Durante os diálogos, foi possível captar que muitos pensam que a profissionalização só é possível a partir de um curso superior. Essa conjectura foi rompida apenas quando um dos jovens relatou que gostaria de realizar algum curso técnico em áreas que lhe trouxessem conhecimento e experiência para que, futuramente, por intermédio do ensino superior, pudesse optar pela mesma profissão. G. U. fala que pretende fazer "[..] técnico de enfermagem ou técnico de farmácia, caso faça algum deles e goste, fará o ensino superior, se necessário." (cf. Diário de campo, 6 de junho de 2011).

A discussão a respeito dos temas propostos mostrou-se positiva e, de fato, contribuiu para que os alunos refletissem e reformulassem suas opiniões. Porém, como modo de maior clarificação das confusões, foram expostos vários vídeos que explicassem os cursos superiores com relatos de alunos, de professores, de coordenadores e de profissionais de cada área atuantes no mercado.

Como finalização do processo em OVP, o quinto encontro propôs sistematizar e refletir todos os encontros anteriores, para que os orientandos assimilassem qual a importância da construção até agora feita. Isto deveria ser feito por eles mesmos inicialmente; caso necessário, ocorreria intervenção.

O diário de campo, como instrumento de trabalho, aqui será usado para demonstrar a elaboração feita pelos jovens: 
A construção lógica que os alunos fizeram ao nosso pedido foi bastante recompensador. Mostraram que durante todo o processo, sempre há escolhas, e essas escolhas os moldam. A família, amigos, gostos musicais/televisivos, pessoas conhecidas e desconhecidas, todos que os cruzam, todos deixam suas marcas, sejam elas grandes ou pequenas. É a partir disso que as escolhas individuais surgirão e influenciarão na hora da decisão, seja essa decisão para vestir uma roupa, ir a uma festa ou escolher uma profissão. (cf. Diário de campo, 13 de junho de 2011).

Muitos do grupo conseguiram chegar sozinhos a esta conclusão, outros com a ajuda dos próprios companheiros, mas o importante é que todos puderam pensar que escolhas devem ser pensadas de acordo com o que se vive. A construção feita em OVP, de acordo com Lehman (1995), conseguiu seu êxito, pois este autor afirma que o papel do psicólogo está além esclarecer situações, está em conscientizar e vincular a problemática juntamente com $\mathrm{o}$ adolescente frente à escolha do seu futuro, pensar em possíveis soluções frente ao contexto e as situações locais onde se vive.

No final, um parecer vocacional/profissional com todo o material recolhido é confeccionado e entregue aos participantes. Tal material contém dados relevantes quanto a aspectos pessoais, sociais e psicológicos do participante, além de dados referentes ao mercado de trabalho e, o mais importante, a escolha profissional. Tal parecer é um feedback tratado de forma ética, pois as informações colhidas nas discussões, tarefas escritas e dinâmicas de grupo não serão entregues a outrem, somente ao participante, com os resultados finais e de forma impressa, podendo ele sanar suas dúvidas diante daquilo que lhe foi apresentado.

Como resultado, pôde-se perceber a formação crítica e a aproximação dos jovens frente às profissões. Esta experiência ímpar con- 
tribuiu para que os jovens consolidassem ideias para adquirir novas possibilidades para suas escolhas, principalmente a profissional.

A cada assunto discutido, era notória a evolução de cada participante e do grupo em geral, pois a cada assunto trabalhado crescia o interesse pelas discussões e as profissões almejadas. $\mathrm{O}$ fardo da obrigatoriedade de escolher uma profissão se desfez, dando lugar a satisfação do trabalho visado na qualidade de vida, seja ela social e econômica, como também psicológica.

\section{Conclusões}

Este projeto contribuiu primeiramente para pôr em prática os conhecimentos teóricos adquiridos durante o processo formativo do bacharel em Psicologia, uma experiência singular e única da utilização das técnicas de processos grupais, como também no acúmulo de vivência que auxilia a construção de um futuro profissional. Logo depois, mas não menos importante, foi auxiliar jovens desprovidos do acesso à informação, capacitando-os de ampla forma à reflexão crítica de suas escolhas.

A adolescência é um estado de transição que está numa vertiginosa transformação, assim como as relações sociais, e essa realidade se torna confusa e difusa. Nesse estado, a inicial proposta de trabalho do psicólogo como orientador vocacional profissional começa pela clarificação dessa confusão (LEHMAN, 1995).

Porém, a falta de publicações na área faz com que muitos profissionais se sintam perdidos em se autodefinirem em relação às problemáticas advindas não apenas das técnicas utilizadas que se diluem, mas em outras questões que sobrepuje a própria área da Psicologia (LEHMAN, 1995). Novas demandas aparecem, novos 
enfrentamentos, novas situações e decisões, e a Psicologia, em particular o psicólogo/orientador, deve estar preparada para orientar esse jovem que está numa fase de escolhas e decisões, de preparo para a vida adulta e de uma definição de carreira. Essas problemáticas são tanto de ordem individual quanto de ordem social.

Assim, o psicólogo que trabalha na orientação vocacional/ profissional de jovens deve sempre ser capaz de compreender o indivíduo a partir de suas relações sociais, de modo a propiciar a construção de uma compreensão acerca dessas relações, bem como sobre a transformação necessária para ampliar a consciência que o próprio indivíduo tem de si mesmo e de sua realidade, ajudando-o a executar suas escolhas, no ensejo de modificar-se e finalizar todas as dificuldades da realidade que o envolve, pensando sempre na promoção da saúde.

Sabe-se que o psicólogo é um profissional da saúde. Na orientação vocacional/profissional é necessário que o psicólogo também trabalhe na promoção da saúde. Só que, como trabalhar promoção à saúde em orientação vocacional/profissional? Prevenção é diferente de promoção. Prevenção remete a palavra prevenir, vinculando a atuação do psicólogo às patologias. Já promoção da saúde, de acordo com Bock e Aguiar (1995, p. 11),

[...] vincula o profissional e sua atuação à saúde no sentido amplo de condições adequadas de vida e de relações saudáveis e volta seu olhar para o indivíduo inserido em seu contexto sócio-cultural, exatamente para poder planejar uma ação capaz de contribuir para a 'promoção da saúde'.

Como o trabalho se desenvolve no campo educacional, observa-se a educação como promotora de saúde. Para tal, usando o termo psicoprofilaxia de Bohoslavsky (1998, p. 11), o orientador 
deve, com uso da análise, utilizar de recursos e técnicas psicológicas apropriadas, "[...] promover o desenvolvimento das potencialidades do ser humano, seu amadurecimento como indivíduo, e finalmente, sua felicidade."

A realização deste trabalho com os jovens de escola pública possibilitou a estes um contato íntimo com a reflexão acerca das diversas escolhas que podem tomar, principalmente a profissional. Experiência esta rica em conteúdo, que trouxe crescimento pessoal tanto a estes alunos, quanto na formação profissional do psicólogo.

Vale também ressaltar que este projeto nos faz pensar várias questões. A importância da implementação da OVP na rede de ensino público, principalmente no ensino médio, possibilitando uma adequação do programa à camada de baixa renda; as contribuições e sugestões de políticas públicas para com esta população, pensando sempre na relação educação e trabalho (BOCK, 2010).

É certo que este trabalho não pretende encerrar aqui as discussões sobre a Orientação Vocacional Profissional, pelo contrário, tem-se como proposta para trabalhos posteriores a formação de novos grupos, sempre buscando superar as dúvidas geradas pelas vastas possibilidades e promover a consolidação e emancipação individual e coletiva de jovens que se encontrem em fases de escolhas, principalmente a profissional.

\section{Referências}

BOCK, A. M. B.; AGUIAR, W. M. J. Por uma prática promotora de saúde em Orientação Vocacional. In: BOCK, S. D.; NASCIMENTO, R. S. von der et al. A escolha profissional em questão. São Paulo: Casa do Psicólogo, 1995. v. 9-22. 
BOCK, S. D. Orientação Profissional: a abordagem Sócio-Histórica. São Paulo: Cortez, 2002.

. Orientação Profissional para as classes pobres. São Paulo: Cortez, 2010.

BOHOSLAVSKY, R. Orientação vocacional: a estratégia clínica. Tradução J. M. V. Bojart. São Paulo: Martins Fontes, 1998. [1974].

CARVALHO, M. M. M. J. de. In: . Orientação Profissional em grupo: teoria e técnica. São Paulo: Psy, 1995. v. 1, cap. 1, p. 21-45.

FRANCO, M. A. S. Educação e Pesquisa. Redalyc, São Paulo, v. 31, n. 3, p. 483-502, set./dez. 2005.

LEHMAN, Y. P. O papel do Orientador Profissional - Revisão crítica. In: BOCK, S. D.; NASCIMENTO, R. S. von der et al. A escolha profissional em questão. São Paulo: Casa do Psicólogo, 1995. v. 239-247.

LANE, S. T. M. L. Consciência/alienação: a ideologia no nível individual. In: ; CODO, W. von der et al. Psicologia Social: o homem em movimento. São Paulo: Brasiliense, 2004. p. 78-98.

. Linguagem, pensamento e representações sociais. In:

CODO, W. von der et al. Psicologia Social: o homem em movimento. São Paulo: Brasiliense, 2004. p. 32-39.

- O processo grupal. In: ; CODO, W. von der et al. Psicologia Social: o homem em movimento. São Paulo: Brasiliense, 2004. p. 78-98.

MELO NETO, J. F. Pesquisa-ação (aspectos práticos da pesquisaação nos movimentos sociais populares e em extensão popular). In: RICHARDSON, Roberto Jarry (Org.). Pesquisa-ação: princípios e métodos. 1. ed. João Pessoa: Editora da Universidade Federal da Paraíba, 2003. v. 1, p. 183-197.

PELISSARI, M. A. O Diário de Campo como instrumento de registro. [S.I.; mimeo], 1998. 
REBOREDO, L. A. De eu e tu a nós: o grupo em movimento como espaço de transformação das relações sociais. Piracicaba: Unimep, 1995.

SILVA, F. F. O atendimento em Orientação Profissional numa instituição pública - modelos e reflexões. In: SILVA, Fabiano Fonseca da (Org.). A escolha Profissional em Questão. São Paulo: Casa do Psicólogo, 1995. v. 1, p. 161-176.

TRIPP, D. Pesquisa-ação: uma introdução metodológica. Educação e Pesquisa, São Paulo, v. 31, n. 3, p. 443-466, set./dez. 2005.

\section{Notas}

* Universidade Federal de Goiás, campus Catalão (UFG/CAC).

** Universidade Federal de Goiás, campus Catalão (UFG/CAC). 
